\title{
ANALISIS KELIMPAHAN UDANG GALAH (Macrobrachium rosenbergii) DI SUNGAI MENDUK KABUPATEN BANGKA
}

\author{
Analysis Of Lobster Abundance (Macrobrachium Rosenbenrgii)On Menduk River \\ Bangka Regency
}

Bobby Fajrilian

Program Studi Manejemen Sumberdaya Perairan, Fakultas Pertanian Perikanan dan Biologi, Universitas Bangka Belitung

Email korespondensi : bobby.fajrilian@gmail.com

\begin{abstract}
Diterima September; disetujui Oktober; tersedia secara online November
\end{abstract}
\begin{abstract}
Menduk River is a river located in Menduk Village, Mendo Barat, Bangka District. Abundance is used to measure and calculate the number of lobster that found in menduk river. It can describe the potential level of lobster present in the Menduk River. The purpose of this study is to calculate the abundance of catches of lobster and to know the parameters of physics and chemistry on menduk river then Analyze the relationship of physical and chemical factors of waters to the abundance of catches lobster. Determination of research station is done by using method of purposive sampling with correlation coefficient analysis. The catch of Galah Udang on March 11 tails and 9 tails in April. The highest correlation coefficient value of water temperature is 0.95 and the lowest value is $\mathrm{pH} 0.14$. The results show that most temperatures influence the catch compared to other physical and chemical parameters.
\end{abstract}

Keyword : Abundance, Physical and Chemical Parameters, Menduk river

\section{PENDAHULUAN}

Sungai Menduk adalah aliran sungai yang terletak di Desa Menduk Kecamatan Mendo Barat Kabupaten Bangka. Menurut Muslih, et al (2014) Sungai Menduk merupakan termasuk sungai yang tercemar sedang. Sungai Menduk yang lebarnya 3 meter dihulu dan lebar sungai dihilir 80 meter dengan panjang sungai 41,91 km (BLHD Provinsi Bangka Belitung, 2015). Sungai Menduk merupakan sungai penghubung dan pemisah antara Desa Kota Kapur dan desa Labuh Air Pandan yang masuk dalam Kecamatan Mendo Barat yang merupakan muara dari beberapa sungai.

Sungai Menduk merupakan sungai yang terkenal dengan potensi komoditas perairan air tawarnya yaitu Udang Galah dan Ikan Baung yang paling ekonomis dan terdapat komposisi jenis ikan ditemukan 21 jenis dari 10 famili (Muslih et al, 2014). Udang Galah pada umumnya sangat digemari masyarakat karena berukuran besar dan gurih, Udang Galah juga menjadi target ekspor dan restoran besar karna memiliki rasa yang enak dan kandungan gizi yang baik (Irianto dan Murdinah, 2006).

Kelimpahan digunakan sebagai ukuran untuk menghitung jumlah suatu spesies. Kelimpahan Udang Galah di Sungai Menduk dapat mendeskripsikan tingkat potensi Udang Galah yang ada di Sungai Menduk. Kelimpahan Udang Galah di Sungai Menduk yang dijadikan sumber sebagai dasar dari pertimbangan dalam pemaanfatan sumberdaya di Sungai Menduk khususnya Udang Galah.

Pemanfatan sumberdaya ikan perairan tawar di Desa Menduk dilakukan dengan berbagai jenis alat penangkapan, yaitu dengan pancing, jaring, serok dan bubu. Salah satu alat tangkap untuk menangkap Udang Galah yaitu dengan menggunakan alat tangkap bubu yang terbuat dari bambu dan kulit kayu. Bubu kulit kayu merupakan alat tangkap Udang Galah yang tradisional yang telah lama digunakan nelayan air tawar Desa Meduk mendapatkan hasil tangkapan berupa Udang Galah. Tingginya tingkat pemanfaatan terhadap tekanan yang signifikan terhadap potensi sumberdaya tersebut. Sehingga perlu adanya informasi tentang kelimpahan Udang Galah di perairan Sungai Menduk. Dengan adanya informasi tersebut dapat memberikan arah pengelolaan yang lebih optimal.

Penelitian ini bertujuan untuk mengetahui parameter fisika dan kimia di Sungai Menduk Kabupaten Bangka; menghitung kelimpahan hasil tangkapan Udang Galah di Sungai Menduk Kabupaten Bangka; dan menganalisis hubungan faktor fisika dan kimia perairan terhadap kelimpahan hasil angkapan Udang Galah di Sungai Menduk Kabupaten Bangka. Manfaat penelitian ini sebagai bahan pertimbangan dalam pengelolaan sumberdaya ikan di Sungai Menduk khususnya Udang Galah di Kabupaten Bangka; sebagai bahan acuan dan refrensi untuk penelitian selanjutnya yang berhubungan kelimpahan Udang Galah di Kabupaten Bangka; dan memberikan data serta informasi kepada masyarakat, akademisi dan pemerintah. 


\section{METODE PENELITIAN}

\section{Tempat dan Waktu Penelitian}

Penelitian ini akan dilakasanakan di Sungai Desa Menduk Desa Menduk Kecamatan Mendo Barat Kabupaten Bangka pada bulan Febuari dan Maret 2017.

\section{Alat dan Bahan Penelitian}

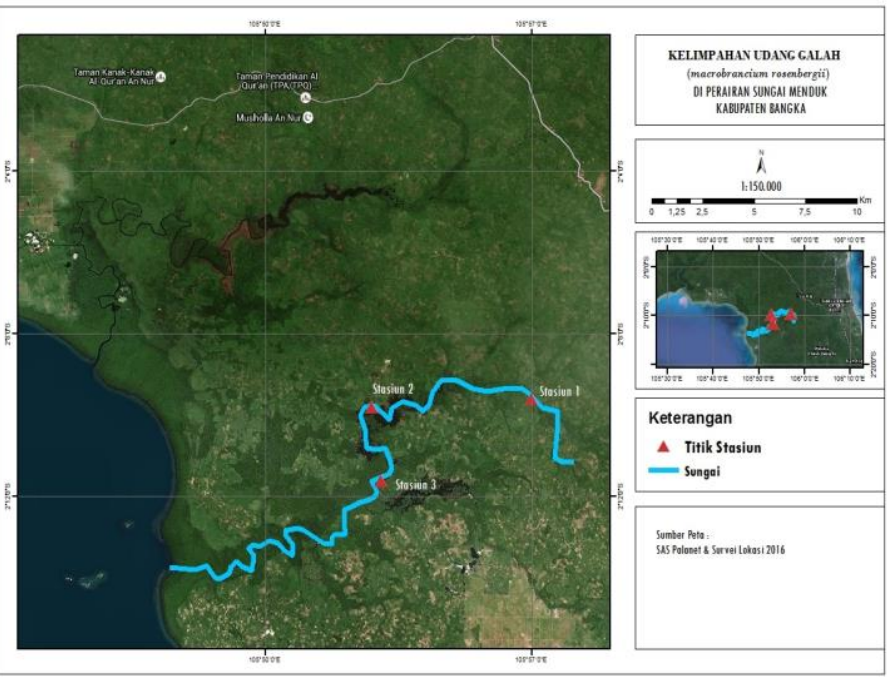

Gambar 1. Lokasi Penelitian

Alat yang digunakan pada penelitian ini adalah alat tangkap bubu kayu yang bentuk memanjang menyerupai keranjang berbentuk torpedo dengan jumlah 30 unit dan masing-masing stasiun dioperasikan sebanyak 10 unit bubu. Secara umum kontruksi bubu kayu memiliki ukuran panjang $36 \mathrm{~cm}$ dan diameter mulut $9 \mathrm{~cm}$, mulut bubu bagian luar berukuran $10 \mathrm{~cm}$ dan diameter $9 \mathrm{~cm}$, mulut bubu bagian dalam berukuran panjang $10 \mathrm{~cm}$ dan diameter $8 \mathrm{~cm}$, sedangkan pintu dari bubu terbuat dari tempurung kelapa dengan diameter pintu $8 \mathrm{~cm}$, bubu juga dilengkapi oleh tali, penanda, dan pemberat. Bahan dasar dari bubu ini adalah kayu, yang dipasang dan dibentuk nelayan menjadi bubu Udang Galah.

Bahan yang digunakan yaitu umpan berupa ubi kayu yang dimasukan ke dalam tiap unit bubu. Ubi dipilih oleh peneliti dikarenakan banyak mengandung zat komposisi yang disukai Udang Galah dan berdasarkan sumber dari hasil wawancara ke beberapa nelayan bahwa nelayan mengunakan ubi yang di masukan kedalam bubu sebagai umpan menarik perhatian Udang Galah. Bagi nelayan Desa Menduk umpan yang efektif dalam menarik perhatian Udang adalah ubi.

\section{Metode Pengambilan Data}

Penentuan stasiun penelitian dilakukan dengan mengunakan metode purpose sampling. Analisis data yang diukur dalam penelitian Udang Galah adalah jumlah dan parameter lingkungan. Peneliti melakukan kegiatan observasi secara langsung di lapangan terhadap objek-objek penelitian. Objek penelitian yaitu data hasil tangkapan Udang Galah dan parameter lingkungan. Berikut pembagian stasiun tersebut adalah:

1. Stasiun 1 terletak di perairan hulu Sungai Menduk yang daerahnya jauh dari aktivitas penambang timah, dan cenderung bersalinitas rendah.

2. Stasiun 2 terletak di tengah sungai atau di antara hulu dan hilir sungai, dan lebih dekat dengan area penambangan timah.

3. Stasiun 3 terletak di hilir sungai yang dominan sebagai daerah penambangan TI apung rakyat, hilir sungai ini juga merupakan daerah yang dekat dengan mulut muara.

Pengoperasian bubu di Sungai Menduk pada penelitian ini dilakukan pada tiga stasiun yang berbeda. Jumlah stasiun ini dipilih agar bertujuan mewakili masing-masing lokasi daerah penelitian. Pada tiap stasiun dilakukan satu kali pengoperasian dengan masing-masing mengunakan sepuluh unit bubu. Pengambilan data dilakukan selama dua bulan dan dalam satu bulan dilakukan satu kali pengambilan data. Dua bulan pengambilan bertujuan untuk melihat perbedaan paremeter lingkungan di dua bulan yg berbeda yang dalam hal ini sangat berhubungan dengan kondisi banyak sedikitnya udang galah.

\section{Metode Pengoprasian Bubu \\ Persiapan}

Bubu yang berjumlah 30 unit disiapkan dengan memasukan umpan berupa ubi singkong yang telah dipotong dan diberi takaran dan kemudian diletakan ke dalam bubu. Setelah persiapan bubu selesai, bubu yang berjumlah 30 unit di masukan kedalam perahu dan kemudian menuju titik stasiun pengambilan data.

\section{Pemasangan}

Bubu yang sudah siap dipasangkan pada tiga stasiun yang telah ditentukan dan dipasang memanjang mengikuti alur sungai dengan 3 perlakuan yang sama dan dengan ukuran yang sama pula yaitu 60 meter sepanjang sungai, 
kemudian peletakan bubu dilakukan dengan hati-hati dan kemudian pasangkan tali diikatkan pelampung yang sudah diikatkan dengan bubu yang berfungsi sebagai penanda agar bubu mudah dikenali.

Lama Perendaman

Lama perendaman bubu pada setiap stasiun yaitu selama 6 jam. Jumlah yang dipasang di setiap stasiun sepuluh unit bubu. Perendaman ini dipilih karena berkaitan dengan mengurangi tingkat kematian Udang Galah jika terlalu lama perendaman, dikarenakan Udang Galah merupakan organisme yang kanibal terhadap sesamanya apabila stok makanan yang ada di dalam bubu sudah habis.

Pengangkatan Bubu (Hauling)

Bubu diangkat setelah waktu perendaman telah selesai sesuia dengan waktu yang telah ditentukan. Bubu diangkat mulai dari pengangkatan pelampung tanda bubu dan dilakukan secara terus menerus hingga bubu yang berjumlah 10 unit terangkat ke atas kapal. Udang Galah yang tertangkap kemudian dimasukan kedalam tempat yang sudah disediakan.

\section{Pengukuran Parameter Fisika dan Kimia}

Parameter lingkungan yang diamati dan diukur secara in-situ dan ex-situ bersamaan dengan proses penangkapan meliputi: suhu, arus, salinitas, $\mathrm{pH}, \mathrm{DO}$ dan pasang surut (ex-situ).

\section{Analisa Data .}

Analisis yang digunakan terhadap data hasil tangkapan yang diperoleh adalah analisis deskriptif. Analisis deskriptif adalah statistik yang digunakan untuk menganalisis data dengan cara mendeskripsikan atau mengambarkan data yang telah terkumpul sebagaimana adanya tanpa bermaksud membuat kesimpulan yang berlaku untuk umum atau generalisasi (Sugiono 2009). Data yang diperoleh dari hasil tangkapan dibuat dalam bentuk tabel dan grafik yang memberi gambaran terhadap hasil penelitian.

Udang galah yang didapat dihitung jumlahnya yang ada disetiap stasiun per sekali trip, kemudian setelah semua data terkumpul dari data semua trip yang dilaksanakan selama 2 bulan dengan 2 kali pengambilan data kemudian di masukan kedalam tabel.

Hubungan parameter lingkungan dengan kelimpahan udang galah dianalisis dengan menggunakan korelasi pearson (r) menunjukan kekuatan hubungan linear, jika positif maka kedua variabel memiliki hubungan searah, sebaliknya jika negatif maka kedua variabel memiliki hubungan terbalik. Koefisien korelasi pearson dapat dicari menggunakan rumus sebagai berikut:

$$
\mathrm{r}=\frac{\mathrm{n} \Sigma \mathrm{xy}-(\Sigma \mathrm{x})(\Sigma \mathrm{y})}{\sqrt{ }\left\{\mathrm{n} \Sigma \mathrm{x}^{2}-(\Sigma \mathrm{x})^{2}\right\}\left\{\mathrm{n} \Sigma \mathrm{y}^{2}-(\Sigma \mathrm{y})^{2}\right\}}
$$

Keterangan :

$\mathrm{x}=$ Variabel terikat

$\mathrm{y}=$ Variabel bebas

$\mathrm{n}=$ Jumlah data

Dengan kriteria menurut Sugiono (2007):

$\begin{array}{ll}\text { Interval Koefisien } & \text { Tingkat Hubungan } \\ 0,00-0,199 & \text { sangat lemah } \\ 0,20-0,399 & \text { Lemah } \\ 0,40-0,599 & \text { Cukup } \\ 0,60-0,799 & \text { Kuat } \\ 0,80-1,00 & \text { sangat kuat }\end{array}$

\section{HASIL DAN PEMBAHASAN}

\section{Hasil}

Berdasarkan penelitian yang dilakukan di Sungai Menduk, Desa Mendo, Kecamatan Mendo Barat, Kabupaten Bangka diperoleh hasil sebagai berikut:

\section{Parameter Kualitas Air}

Hasil pengukuran parameter lingkungan selama penelitian di Sungai, didapatkan nilai yang berbeda antar stasiun pengamatan. 
Tabel 1. Hasil pengukuran parameter lingkungan di Sungai Menduk pada bulan Maret dan April

\begin{tabular}{lllllll}
\hline & \multicolumn{3}{c}{ Bulan Maret } & \multicolumn{3}{c}{ Bulan April } \\
\cline { 2 - 7 } Parameter & Stasiun 1 & Stasiun 2 & Stasiun 3 & Stasiun 1 & Stasiun 2 & Stasiun 3 \\
\hline Suhu Air $\left({ }^{0} \mathrm{C}\right)$ & 27,3 & 28 & 27,3 & 27,6 & 28,3 & 27,6 \\
Arus $(\mathrm{m} / \mathrm{s})$ & 0,26 & 0,30 & 0,36 & 0,25 & 0,29 & 0,36 \\
$\mathrm{pH}$ & 5,6 & 5,6 & 5,3 & 5 & 5,6 & 5,3 \\
DO $(\mathrm{mg} / \mathrm{L})$ & - & - & - & 2,87 & 3,37 & 3,03 \\
Salinitas & 0 & 0 & 0 & 0 & 0 & 3 \\
\hline
\end{tabular}

Kelimpahan Hasil Tangkapan Udang Galah

Hasil penelitian kelimpahan yang ditemukan di lokasi sampling berkisar $2-6$ ekor, dengan total 11 ekor pada bulan Maret dan 9 ekor pada bulan April. Kelimpahan tertinggi terdapat pada stasiun 2 dan kelimpahan terendah terdapat pada stasiun 3 di Sungai Menduk. Kelimpahan Udang Galah dapat dilihat pada (Tabel 2).

Tabel 2. Jumlah Tangkapan Udang Galah Per Bulan

\begin{tabular}{llllll}
\hline \multirow{2}{*}{ No } & \multirow{2}{*}{ Bulan } & \multicolumn{4}{c}{ Jumlah Tangkapan } \\
\cline { 3 - 6 } & & stasiun 1 & stasiun 2 & stasiun 3 & Total \\
\hline 1 & Maret & 3 ekor & 6 ekor & 2 ekor & 11 ekor \\
2 & April & 3 ekor & 4 ekor & 2 ekor & 9 ekor \\
\hline
\end{tabular}

Hubungan Kelimpahan Udang Galah Dengan Parameter Fisika Dan Kimia Perairan

Berdasarkan hasil analisis korelasi menggunakan Pearson Correlation Coefficient maka kelimpahan Udang Galah memiliki hubungan erat dengan suhu, DO dan salinitas (Tabel 3).

Tabel 3. Nilai hubungan antara kelimpahan Udang Galah dengan parameter fisika kimia perairan di Sungai Menduk.

\begin{tabular}{lcc} 
Parameter & Koefisien korelasi & Hubungan \\
\hline Suhu Air $\left({ }^{0} \mathrm{C}\right)$ & 0,95 & Sangat Kuat \\
Arus $(\mathrm{m} / \mathrm{s})$ & $-0,38$ & Lemah \\
$\mathrm{pH}$ & 0,14 & Sangat Lemah \\
$\mathrm{DO}(\mathrm{mg} / \mathrm{L})$ & 0,80 & Sangat Kuat \\
Salinitas & $-0,76$ & Kuat \\
\hline
\end{tabular}

Keterangan:Nilai Koefisien Korelasi didapat dari nilai hasil kelimpahan dan nilai parameter lingkungan yang telah diolah dengan menggunakan Rumus Koefisien Korelasi

\section{Pembahasan}

\section{Parameter Fisika dan Kimia Sungai Menduk}

Suhu perairan di Sungai Menduk cenderung seragam, yaitu berkisar antara $26^{\circ} \mathrm{C}-29^{\circ} \mathrm{C}$ dengan nilai rata-rata 27,65 ${ }^{\circ} \mathrm{C}$ di semua stasiun ketika dilakukan sampling pada bulan Maret dan April. Menurut Effendi (2003), bahwa suhu demikian sangat baik bagi pertumbuhan fitoplankton di perairan yang memiliki kisaran suhu optimum $20^{\circ} \mathrm{C}-30^{\circ} \mathrm{C}$ Pertumbuhan fitoplankton yang baik merupakan ketersediaan makanan pula bagi ikan. Hasil sampling menunjukkan terjadinya dinamika perubahan suhu dari 3 jam pengamatan, hal ini disebabkan cahaya matahari terik saat pukul 12.00 13.00 WIB yang kemudian hujan turun pada pukul 14.35 - 16.40 WIB yang secara otomatis dapat merubah suhu perairan. Menurut Rizaldi (2015), menyatakan jika tingginya suhu akan meningkatkan metabolisme suatu biota di perairan, dan sebaliknya apabila suhu menurun maka secara otomatis metabolisme juga akan turun. Metabolisme meningkat jika suhu meningkat walaupun hanya $1^{0} \mathrm{C}$ (Effendi, 2003).

Derajat keasaman atau $\mathrm{pH}$ perairan di Sungai Menduk cenderung asam dengan kisaran $5-6$ dan rata-rata $\mathrm{pH} 5$. Kondisi $\mathrm{pH}$ yang asam di Sungai Menduk ini diduga karena terjadinya aktivitas tambang yang memungkinkan Sungai Menduk menjadi asam. Menurut Muslih (2014), pH asam ini diduga terjadi akibat dampak dari penambangan timah. Sifat asam terbentuk dari proses oksidasi batuan/mineral sulfida seperti pirit $\left(\mathrm{FeS}_{2}\right)$ dari mine tailing, batuan buangan tambang atau dinding batuan yang diikuti oleh oksidasi besi ferous [ $\mathrm{Fe}(\mathrm{II})]$ melepaskan ion hidrogen dan sulfat yang bereaksi membentuk asam sulfat (Luis et al, 2011). 
Arus merupakan faktor yang memiliki peranan penting pada perairan sungai. Hal ini berhubungan dengan penyebaran organisme, gas-gas terlarut dan mineral yang terdapat di dalam air. Penggolongan kecepatan arus di Sungai Menduk dalam penelitian ini termasuk ke dalam kategori arus sedang yaitu dengan nilai 0,26 $\mathrm{m} /$ detik pada stasiun 1 kemudian $0,30 \mathrm{~m} /$ detik pada stasiun 2 dan 0,36 m/detik pada stasiun 3. Menurut Harahap dalam Sari et al (2012), mennyatakan bahwa penggolongan kecepatan arus terdiri atas 4 kategori yaitu kategori arus lambat dengan kecepatan pada kisaran $0-0,25 \mathrm{~m} /$ detik, kategori arus sedang dengan kecepatan pada kisaran 0,25 - 0,50 m/detik, kategori arus cepat dengan kecepatan pada kisaran 0,5 - $1 \mathrm{~m} /$ detik dan kategori arus sangat cepat dengan dengan kecepatan di atas 1 $\mathrm{m} /$ detik. Arus lambat sampai sedang memungkinkan banyaknya partikel-partikel makanan yang bersumber dari daerah hulu, maupun jatuhan serangga dan daun dari pepohonan yang tertahan lama di badan perairan merupakan sumber makanan bagi organisme perairan. Menurut Barus (2000), sungai yang berarus lambat sampai sedang merupakan habitat yang sangat ideal bagi organisme air yang tidak mempunyai adaptasi khusus melawan arus air yang deras. Kecepatan arus pada dasarnya disebabkan oleh sifat air yang mengalir dari hulu ke hilir dan pada bagian hulu sungai lebih deras dibandingkan hilir sungai di karenakan tingkat kemiringan yang lebih tinggi dan badan perairan yang relatif lebih sempit dibandingkan dengan daerah hilir.

Kecepatan arus yang sedang di Sungai Menduk dengan kecepatan yang berbeda pada setiap stasiunya di sebabkan oleh tertahan tumbuhan air yang mendominasi di perairan Sungai Menduk sehingga dapat menahan dan meredam kecepatan arus.

Kandungan oksigen terlarut di Sungai Menduk tergolong rendah, tetapi masih layak untuk kehidupan ikan yaitu dengan nilai rata-rata sebesar 2,86 mg/L pada stasiun 1 kemudian 3,36 mg/L pada stasiun 2 dan 3,03 mg/L pada stasiun 3. Menurut pescod (1973) dalam haryono (2001), kadar oksigen terlarut yang baik bagi ikan minimal $3 \mathrm{mg} / \mathrm{L}$, sedangkan menurut New (2002), kisaran optimum oksigen terlarut udang galah yaitu 3-7 mg/L dengan batas lethal kurang dari $1 \mathrm{mg} / \mathrm{L}$. Oksigen terlarut dalam perairan dapat bersumber dari difusi oksigen yang terdapat di atmosfer dan aktivitas fotosintesis dari fitoplankton. Kadar oksigen terlarut yang ada pada sungai menduk cenderung rendah. Rendahnya oksigen terlarut diduga tingginya tutupan kanopi di sekitar sungai, yang umumnya didominasi pandan air, sehingga terbentuknya oksigen melalui proses fotosintesis ke badan perairan kurang berjalan dengan baik.

Hasil sampling menunjukan pada bulan Maret ditemukan kadar salinitas di ketiga stasiun, tetapi ketika sampling pada bulan April ditemukan kadar salinitas di stasiun 3, dengan kadar nilai salinitas 3 ppt, hal ini diduga karena sampling pada bulan April tidak turun hujan dengan panas yang terik, sehingga waktu terjadinya aktivitas pasang surut masih menerima dorongan dan pasokan dari pasangnya air laut dan stasiun 3 paling dekat berada di muara sungai di bandingkan stasiun 1 dan 2 tetapi sebaliknya sampling pada bulan Maret terjadi turun hujan dan mendapat pasokan air tawar dari darat yang bermuara ke sungai sehingga salinitas tidak ditemukan di 3 stasiun pada bulan Maret. Pasang surut menentukan nilai salinitas di suatu sungai, pengambilan data pada bulan maret pada pukul 10.00-14.00 sedang pasang besar. Menurut kurniadi et al (2015), rata-rata salinitas saat pasang lebih besar daripada saat surut.

\section{Kelimpahan udang galah}

Secara keseluruhan kelimpahan tertinggi selama penelitian di Sungai Menduk yaitu terdapat pada stasiun 2 dibandingkan dengan stasiun 1 dan 3. Hal ini diduga karena di stasiun 2 memiliki DO yang paling tinggi dibandingkan dengan stasiun 1 dan 3. Menurut effendi (2003), oksigen merupakan salah satu gas yang terlarut dalam perairan. Kadar oksigen yang terlarut di perairan alami bervariasi tergantung pada suhu, salinitas, turbulensi air dan tekanan atmosfer. Nilai rata-rata DO 3,37 pada stasiun 2 kemudian 3,03 pada stasiun 3 dan 2,87 pada stasiun 1, dari hasil sampling kelimpahan tertinggi terdapat pada stasiun 3, ini menujukkan bahwa semakin tinggi DO maka kelimpahan akan semakin tinggi. Menurut new (2002), kandungan oksigen terlarut yang optimal untuk Udang Galah berkisar 3-7 $\mathrm{mg} / \mathrm{liter}$, dan menimbulkan stress jika di bawah $2 \mathrm{mg} / \mathrm{liter}$.

Kelimpahan Udang Galah dimasing-masing stasiun pada saat sampling berbeda-beda. Pengambilan data pada bulan Maret mendapatkan data hasil tangkapan 11 ekor Udang Galah dan diantaranya terbagi dalam 3 stasiun, yaitu 2 ekor pada stasiun 1, 6 ekor pada stasiun 2 dan 3 ekor pada stasiun 3, sedangkan pada pengambilan data bulan April jumlah udang lebih sedikit dibandingkan dengan bulan Maret yaitu 3 ekor pada stasiun 1, 4 ekor pada stasiun 2 dan 2 ekor pada stasiun 3, tetapi apabila dilihat dari segi hasil kuantitas jumlah Udang Galah yang didapat pada 2 bulan pengambilan data, bulan Maret mendapatkan hasil tangkapan Udang Galah yang lebih banyak yaitu total hasil tangkapan 11 ekor daripada pengambilan data pada bulan April, tetapi apabila dilihat dari segi kuantitas berat udang total hasil tangkapan, hasil tangkapan pada bulan April lebih berat dibandingkan hasil tangkapan pada bulan Maret.

Bulan Maret dan April ketika sampling ditemukan Udang Galah yang sedang bertelur, pada bulan Maret ditemukan 3 ekor Udang Galah yang bertelur dengan ukuran panjang udang galah pada stasiun 1 yaitu $12,1 \mathrm{~cm}$ dan 15 $\mathrm{cm}$, sedangkan ukuran panjang pada stasiun 3 yaitu 13,5 cm. Sampling bulan April ditemukan 2 Udang Galah yang sedang bertelur, keduanya ditemukan di stasiun 3, dengan ukuran panjang udang 13,9 cm dan 18,7 cm. Bulan Februari sampai Maret Udang Galah sudah benar-benar memijah dengan jumlah telur berkisar 40.000 sampai 108.000 butir pada udang ukuran 12-16 cm (Utomo, 2001).

Kelimpahan tertinggi dari sampling yang telah dilakukan pada stasiun 2 yaitu dengan total hasil tangkapan bulan Maret - April 10 ekor, ini menunjukkan bahwa pada stasiun 2 ini merupakan daerah yang disukai oleh Udang Galah, ini juga disebabkan daerah pada stasiun 2 lebih baik dari faktor tutupan vegetasi pepohonan yang cenderung terbuka untuk cahaya matahari dapat masuk langsung ke perairan, dibandingkan stasiun 1 dan 3 cenderung tertutup oleh 
pepohonan dan teduh dari cahaya matahari sehingga suhu menjadi rendah di perairan sehingga menyebabkan Udang Galah jarang makan, karena udang galah besifat hewan berdarah panas dan aktif mencari makan ketika suhu perairan meningkat.

Menurut Gustomi (2012), suhu menjadi faktor pembatas karena mampu mempengaruhi berbagai reaksi fisika dan kimia di lingkungan dan tubuh ikan. Suhu terkait juga dengan parameter kualitas air lainya, diantaranya adalah oksigen terlarut. Pada level suhu yang meningkat, kandungan oksigen berkurang karena proses metabolisme lebih cepat. Setiap kenaikan suhu sebesar $10^{\circ} \mathrm{C}$ akan meningkatkan kecepatan reaksi kimia dalam proses metabolisme organisme perairan hampir dua kali lipat (Ropiah dan Mahyuddin, 2000). Udang Galah memiliki kisaran suhu yang optimal untuk mendukung tumbuh dan berkembang. Menurut Spotts (2001), Udang Galah hidup optimal pada suhu air berkisar antara $26-30^{\circ} \mathrm{C}$.

Ketersedian pakan di perairan juga ditentukan dari penetrasi cahaya yang masuk ke perairan, karena pada saat penetrasi cahaya rendah ke dalam perairan menyebabkan fitoplankton tidak maksimal dalam melakukan fotosintesis. Fitoplankton adalah organisme yang dapat mengubah zat-zat anorganik menjadi zat organik dengan bantuan cahaya matahari melalui proses fotosinteis yang hasilnya disebut produksi primer dan juga sebagai pemasok oksigen. Ketika penetrasi cahaya ke perairan rendah, maka fotosintesis akan terhambat dan zat organik di perairan rendah. Oleh sebab itu ketersedian makanan di perairan rendah (Safitriyani, 2015).

\section{Hubungan Parameter Lingkungan dengan Kelimpahan Udang Galah}

Berdasarkan hasil analisis korelasi maka kelimpahan Udang Galah di sungai menduk memiliki hubungan erat dengan DO, suhu, dan salinitas. Arus air merupakan pergerakan massa air dari daerah yang tinggi ke daerah yang rendah sesuai dengan sifat air. Berdasarkan hasil perhitungan koefisien korelasi yang bernilai negatif yaitu -0,38. Semakin tinggi arus di sungai menduk maka nilai kelimpahan udang galah di sungai menduk semakin sedikit. Batas toleransi ikan mampu hidup optimal di kisaran arus antara 0,56-0,67 m/s (Marcel et al, 2014).

Oksigen terlarut atau DO merupakan jumlah gas $\mathrm{O}_{2}$ yang diikat oleh molekul air. Sumber utama DO dalam perairan adalah dari proses fotosintesis tumbuhan dan penyerapan/penyerapan secara langsung oksigen dari udara melalui kontak antara permukaan air dengan udara. Berdasarkan hasil perhitungan koefisien korelasi yaitu bernilai 0,95 yang artinya semakin tinggi nilai DO perairan maka semakin tinggi juga kelimpahan udang galah di sungai menduk dan kebalikannya apabila semakin rendah nilai koefisien korelasi maka semakin rendah nilai dari kelimpahan Udang Galah di Sungai Menduk

Berdasarkan hasil analisis korelasi hubungan antara kelimpahan suhu cukup tinggi dibandingkan dengan nilai korelasi lainnya. Menurut nilai hasil korelasi semakin tingginya nilai korelasi maka semakin tinggi nilai kelimpahan dan kebalikanya apabila semakin rendah nilai koefisien korelasi maka semakin rendah pula nilai kelimpahan Udang Galah di Sungai Menduk. Suhu merupakan faktor pembatas bagi biota perairan dan suhu juga merupakan suatu faktor yang dapat mempengaruhi aktivitas makan organisme perairan, seperti ikan dan Udang Galah karena bersifat hewan berdarah panas yang aktif mencari makan ketika suhu perairan cederung meningkat, dan ketika suhu menurun udang galah lebih cenderung diam atau bersembunyi dan tidak aktif mencari makan. Pada level suhu yang meningkat, kandungan oksigen berkurang karena proses metabolisme lebih cepat. Setiap kenaikan suhu sebesar $10^{\circ} \mathrm{C}$ akan meningkatkan kecepatan reaksi kimia dalam proses metabolisme organisme perairan hampir dua kali lipat (Ropiah dan Mahyuddin, 2000).

Salinitas didefinisikan sebagai konsenterasi total semua ion yang terlarut dalam air (Boyd, 1982). Berdasrkan hasil, nilai salinitas memiliki nilai koefisien korelasi yang negatif terhadap kelimpahan udang galah di Sungai Menduk, yang artinya semakin tinggi nilai negatif dalam analisis koefisien korelasi maka semakin rendah pula nilai kelimpahan. menurut Hamzah (2004), Udang Galah dewasa merupakan penghuni sungai yang ada hubungannya dengan laut seperti danau, rawa dan waduk. Udang Galah dewasa cenderung lebih banyak hidup pada lingkungan tawar, tetapi pada saatsaat tertentu udang galah bermigrasi menuju perairan bersalinitas pada saat akan memijah dan pada saat fase pembesaran larva. Siklus hidup Udang Galah secara alami memerlukan lingkungan air payau dan air tawar (Toro dan Sugiarto, 1979).

Derajat keasaman atau $\mathrm{pH}$ merupakan ukuran konsentrasi ion hidrogen yang menunjukkan suasana asam atau basa suatu perairan. Nilai $\mathrm{pH}$ yang rendah dapat mengganggu pertumbuhan dan kelangsungan hidup Udang Galah, karena dapat menyebabkan Udang Galah menjadi stress dan kerapas Udang Galah menjadi lembek. Menurut Muslih (2013), pada umumnya Kondisi perairan asam memang menjadi ciri perairan di sebagian besar wilayah pulau Bangka. Berdasarkan hasil nilai analisis koefisien korelasi nilai $\mathrm{pH}$ adalah nilai positif yang paling rendah nilainya, yang artinya pH yang ada di Sungai Menduk tidak begitu mempengaruhi dari nilai kelimpahan Udang Galah.

\section{KESIMPULAN DAN SARAN}

\section{Kesimpulan}

1. Parameter fisika dan kimia di Sungai Menduk untuk suhu berkisar $26^{\circ} \mathrm{C}-20^{\circ} \mathrm{C}$, arus $25-36 \mathrm{~m} / \mathrm{detik}, \mathrm{pH}$ air 5 - 6 kemudian DO 2,7 - 3,4 mg/L dan salinitas $0-3$ ppt yang hanya ditemukan pada stasiun 3 pada waktu sampling bulan April. 
2. Kelimpahan Udang Galah di Sungai Menduk didominasi pada stasiun 2 dengan jumlah total 10 ekor kemudian 6 ekor terdapat pada stasiun 1 dan kelimpahan paling rendah terdapat pada stasiun 3 dengan jumlah total 4 ekor yang didapat selama sampling dilakukan.

3. Tingkat hubungan paling erat pada penelitian adalah suhu perairan dengan nilai koefisien korelasi 0,95 dan DO dengan nilai 0,80 kemudian tingkat hubungan paling rendah adalah dengan nilai $\mathrm{pH} 0,14$ kemudian arus dengan nilai $-0,38$ dan salinitas dengan nilai $-0,76$.

\section{Saran}

Perlu dilakukan penelitian lanjutan tentang komposisi ukuran Udang Galah di Sungai Menduk yang dilakukan sepanjang musim selama satu tahun untuk melihat komposisi ukuran disetiap stasiun dan pada sepanjang bulan.

\section{UCAPAN TERIMA KASIH}

Isi ucapan terimakasih ditulis menggunakan font times new roman 10 dengan spasi 1. Ucapan terima kasih ditulis dengan jelas dan ringkas kepada siapa ucapan terima kasih itu diberikan. Misalnya penelitian yang dibiayai (DIPA, hibah dan sponsor) atau orang/intasni yang berperan membantu penelitian.

\section{DAFTAR PUSTAKA}

Ali, F. 2009. Mendongkrak Produktivitas Udang Galah Hingga 250 Persen. Penebar Swadaya. Jakarta.

Badan Lingkungan Hidup Daerah (BLHD) Provinsi Kepulauan Bangka Belitung. 2015. Laporan Kegiatan Pemantauan Kualitas Air Sungai dan Penentuan Status Mutu Sungai Provinsi Kepulauan Bangka Belitung.

Barus, T.A. 2000. Penghantar Limnologi. Universitas Sriwijaya: Palembang.

Effendi, H. 2003. Telaah Kualitas Air Bagi Pengelolaan Sumber Daya dan Lingkungan Perairan. Kanisius, Yogyakarta.

Guntur. 2006. Pengaruh Pemberian Bakteri Probiotik Vibrio skt-b Melalui Artemia Terhadap Pertumbuhan dan Kelangsungan Hidup Larva Udang Windu (Penaeus monodon Fab.) [Skripsi]. Institut Pertanian Bogor. Bogor.

Gustomi A. 2012. Keanekaragaman Jenis Ikan Di Perairan Sungai Penyerang Kecamatan Puding Besar Kabupaten Bangka. [Skripsi]. Jurusan Manejemen Sumberdaya Perairan Fakultas Pertanian Perikanan Dan Biologi. Universitas Bangka Belitung.

Hadie, L.E dan Hadie, W. 2002. Budidaya Udang Galah GIMacro. Penebar Swadaya. Jakarta.

Hamzah, M. 2004. Kelangsungan hidup dan pertumbuhan juvenil Udang Galah (Macrobrachium rosenbergii) pada berbagai tingkat salinitas media. [Tesis]. Program Pascasarjana, Institut Pertanian Bogor, Bogor.

Haryono. 2001. Biodiversitas Ikan Di Kawasan Rehabilitas Bakau Paojepe Kabupaten Wajo Sulawesi Selatan. Zoo Indonesia (28): 26-35.

Irianto, H.E dan Murdinah. 2006. Keamanan Pangan Produk Perikanan Indonesia. Di dalam proshiding seminar naional PATPI. yogyakarta 2-3 agustus. 2006. Hal 116-126.

Kurniadi B., Hariyadi S dan Adiwilaga E.M. 2015. Kualitas Perairan Sungai Buaya di Pulau Bunyu Kalimantan Utara pada Kondisi Pasang Surut. Jurnal Ilmu Pertanian Indonesia (JIPI). Vol. 20 (1): 5358.

Luis, A.T., Teixeira P., Almeida S.F.P., Matos J.X., da Silva E.F. 2011. Environmental impact of mining activities in the Lousal area (Portugal): Chemical and diatom characterization of metal-contaminated stream sediments and surface water of Corona stream. Science of the Total Environment. 409:4312-4325. doi:10.1016/j.scitotenv.2011.06.052.

Mamesah, J dan Latuihamalloh, M. 2007. Struktur Komunitas Bivalvia Pada Komunitas Mangrove Desa Passo Kecamatan Teluk Ambon Baguala, Maluku. Prosiding seminar nasional muluska dalam penelitian, konservasi dan ekonomi. Semarang 17 juli 2007.

Marcel A.A., Setyawati T.R dan Yanti A.H. 2014 Keragaman Jenis Ikan Arus Deras di Aliran Riam Banangar Kabupaten Landak. Jurnal Protobiont Vol. 3(2) : 209 - 2017.

Mawardi, M.M. 2001. Pengaruh Penggunaan Jenis Umpan Terhadap Hasil Tangkapan Ikan Karang pada Alat Tangkap Bubu (Trap) di Pulau Pramuka, Kepulauan Seribu [skripsi]. Fakultas Perikanan, Institut Pertanian Bogor. Bogor $63 \mathrm{hlm}$.

Muslih K., Adiwilaga E.M dan Adiwibowo S. 2014. Habitat Characteristics and Biodiversity of Freshwater Fish in Menduk River that Got Influence Tin Mining in Bangka. Jurnal Sumberdaya Perairan. 8(2): 22.

New, M.B. 2002. Farming freshwater prawns a manual for the culture of the giant river prawn Macrobrachium rosenbergii. FAO Fisheries, United Kingdom.

Praseno, O., Hadie,W dan Hadie, L.E. 2001. Distribusi Geografis dan Karakteristik Ekologi Udang Galah. Prosiding Workshop Hasil Penelitian Udang Galah, 26 Juli 2001, Jakarta.

Rizaldi. 2015. Kelimpahan Kepiting Bakau (Scylla sp.) Di Perairan Muara Tebo Nelayan 1 Sungailiat [Skripsi]. Jurusan Manejemen Sumberdaya Perairan Fakultas Pertanian Perikanan Dan Biologi. Universitas Bangka Belitung.

Ropiah, S, dan Mahyuddin K. 2000. Pengelolaan Kualitas Air: Keterampilan Pertanian Budidaya Ikan. Grafika, Jakarta. Safitriyani, E. 2015. Aspek Reproduksi Ikan Kurisi (Nemipterus Furcosus) Yang Didaratkan Di Pelabuhan Perikanan Nusantara Sungailiat (Studi Kasus:Hasil Tangkapan Bulan Desember 2014 Sampai Februari 2015). [Skripsi]. 
Jurusan Manejemen Sumberdaya Perairan Fakultas Pertanian Perikanan Dan Biologi. Universitas Bangka Belitung.

Sari T.E.Y dan Usman. 2012. Studi Parameter Fisika dan Kimia Daerah Penangkapan Ikan Perairan Selat Asam Kabupaten Kepulauan Meranti Provinsi Riau. Jurnal Perikanan dan Kelautan. 17(1) : 88-100.

Spotts, D. 2001. Introducing Macrobrachium Rosenbergii. Freshwater and Marine Aquarium: 4(7):32-34 \& 74-75. http://www.miami-aquaculture.com. [20 Juni 2009].

Sudirman., Irnawati N dan Susanto A. 2004. Penggunaan Jenis dan Bobot Umpan yang Berbeda pada Bubu Lipat Kepiting Bakau. Jurnal Ilmu Pertanian Dan Perikanan. 2 (1) : 55-61.

Sugiyono. 2007. Metode Penelitian Bisnis. CV. Alfabeta. Bandung.

Toro V dan Sugiarto K.A. 1979. Biologi Udang : Statistik, Morfologi, Daur Hidup, Habitat Dan Makanan. hal 1-44, Eds. Udang. LON LIPI, Jakarta.

Utomo AD. 2001. Ruaya dan Pertumbuhan Udang Galah (Macrobrachium rosenbergii De Man) di Sungai Lempuing Sumatera Selatan [Tesis]. Bogor (ID): Institut Pertanian Bogor. 